Anthropogenetical Institute of the State University

and Royal Institute for the Deaf, Groningen, The Netherlands

\title{
Dysostosis mandibulo-facialis (Franceschetti-Zwahlen) in four generations
}

\section{S. Wildervanck}

This syndrome, extensively described by Franceschetti and Klein, Waardenburg and Navis, Nager and de Reynier, and of which Zunin gave a short description in a paper on two homozygous cases in this Journal, is probably not so rare as formerly was thought. Until now more than a hundred cases have been published among which about 25 are transmitted hereditarely, after Franceschetti, Klein and Brocher already I 50 cases totally. The mode of heredity appeared to be dominant, in some of the pedigrees the heredity seems to be irregularly dominant. The far greater part of the pedigrees however consists of very few persons. The leading symptom is an "anti-mongoloid" obliqueness of the palpebral fissures. Moreover there exists a hypoplasia of the os zygomaticum or the processus zygomaticus ossis temporalis, and of the mandibula. Often the auricles are developed insufficiently, in severe cases there exists microtia and atresia of the external auditory canals and malfomation of the middleear. The greater part of the affected persons shows a conductive deafness in a variable degree. A further symptom may be macrostomia and malocclusion of the teeth. The expressivity of all those symptoms is very variable, some affected individuals may show only a forme fruste of few significance, other persons may be fully monstrous. Intra-familial variability is proved clearest by the greater pedigrees published by Debusman (three generations), Leopold e. a. (a negro family of four generations), Roussel (four generations), Böök and Fraccaro (two generations), Gayral, Schachter (two generations) and Hövels.

The greater part of the affected members, formes frustes included, shows a more or less impaired hearing, of 32 patients of the literature in whom the syndrome was hereditary, ig were more or less deaf. The penetration of the syndrome seems to be rather low in some pedigrees, in other families however, it is rather high. As too few large pedigrees have been published, it is impossible to get a well founded opinion about the penetration. The present investigation deals with a family of four generations in which five members show the D. M. F. syndrome (Fig. I).

I, 3. Photogram of a familyportrait (Fig. 2). The eyes show a slight anti-mongoloid obliqueness, the ears are implanted lowly, there exists a slight degree of micrognathy. The man was very hard of hearing. 
II, 5. (Fig. 3). Palpebral fissures slightly oblique, the ears are normal, underdevelopment of the mandibula. The lady is very hard of hearing.

III, 2. (Fig. 4). $3^{\text {I }}$ years old. Slight anti-mongoloid position of the eyes, the ears are somewhat curved forward. The man hears very badly with his left ear, cannot use the telephone at this ear. With the right ear he is able to hear a whispering voice at a distance of three meters. The mandibula is underdeveloped.

III, 5. Pupil of the School for hard of hearing children, born in I940 (Fig. 5). He shows the syndrome in a very severe form. At the left as well at the right side microtia and atresia auris. In his early youth a surgeon tried to reconstruct the ears in vain. The eyes show an extensive anti-mongoloid position. Coloboma of the lateral part of the lower lids, at the right side more pronounced than at the left side. The lower lids lack eye lashes. The mouth is large (macrostomia), the palatum is ogival. The mandibula is badly developed, irregular position of the teeth. The impairment of hearing is of a complete conductive kind (audiogram Prof. H. C. Huizing, Audiological Dep. of the University Hospital) : loss of hearing of $70 \mathrm{db}$. along the whole tone scale. Bone conduction normal. Röntgenogram (Röntgen. Institute of the University Hospital, Th. Niemeijer), (Fig. 6) : the underdevelopment of the mandibula is obvious. Orbitae oblique, the lateral part of the orbitae is irregularly formed, the orbital part of the os zygomaticum is lacking at both sides.

IV, 2. (Fig. 7). Pupil of the School for hard of hearing children, 6 years old. Obliquity of the eyes, no colobomes. Ears curved forward, underdevelopment of the chin. Conductive deafness, the audiogram shows a loss of hearing of 60 to $80 \mathrm{db}$. along the whole tone scale, bone conduction normal. When touching the malar bones, one gets the impression that the orbital part of the os zygomaticum is lacking. Röntgenogram: "especially at the left side there seems to be an insufficient development of the os zygomaticum".

The dominant hereditary transmission in this family is obvious, the penetration seems to be rather great and the variability of the expressivity of the syndrome is great - as it is in other pedigrees published. The obliqueness of the palpebral fissures, the "leading symptom", is never lacking. Four of the five affected persons are suffering from a severe degree of impairment of hearing, the fifth, III, 2 shows this in a less severe form. In two members, III, 5 and IV, 2, who show the syndrome in a classic form, a defect of the os zygomaticum could be verified röntgenologically. Dysostosis mandibulo-facialis in four generations has only twice been published (Leopold e. a., Roussel), most pedigrees consist of only a parent and one or two children. Many authors get the impression that in next generations the affection becomes more severe. This indeed holds good for many pedigrees (Freudenberg, Schachter, Brohm and Kluska (cit. Franceschetti and Klein), Weyers (unilateral form), Roussel, Debusman). In the pedigree of Leopold e. a. however, this is not the case. As mentioned already most pedigrees are small! Moreover in many cases the authors don't mention their findings about the hearing clearly. Considering this in the present family, it can be statet that I, 3 and II, 5 show a rather normal face, though typical for a light form of D. M. F. but they have a severe impairment of hearing. III, 2 has about the same face, but his impairment of hearing is only so slight that one can speak with him without being obliged to raise his voice. His brother, III, 5 however shows the syndrome in optima 


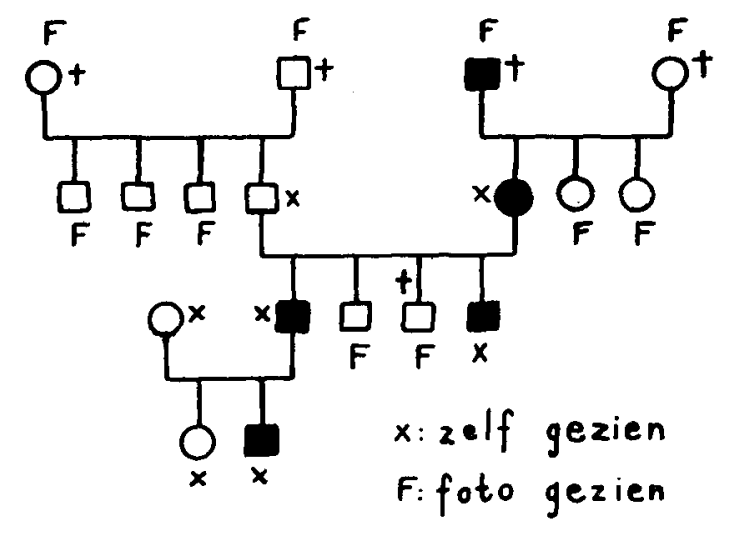

Fig. I. A cross $=$ examined by the author $\mathrm{F}=$ photo seen by him.

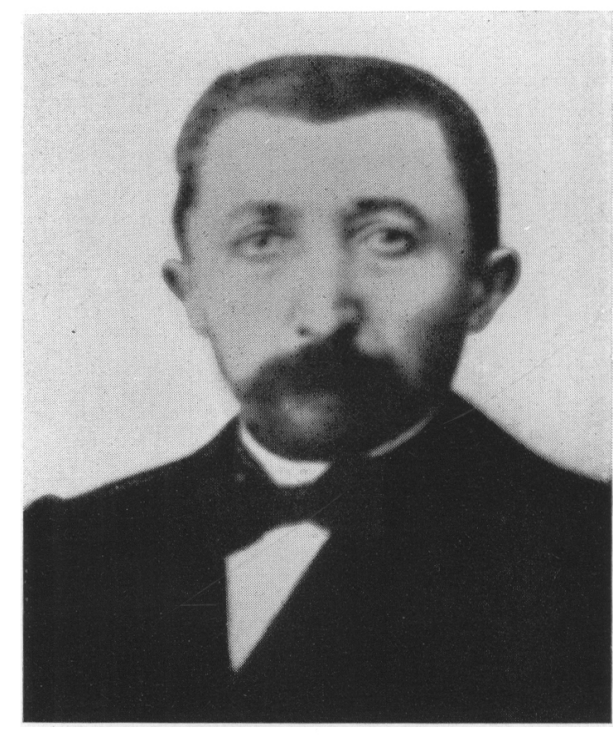

Fig. $2(I, 3)$
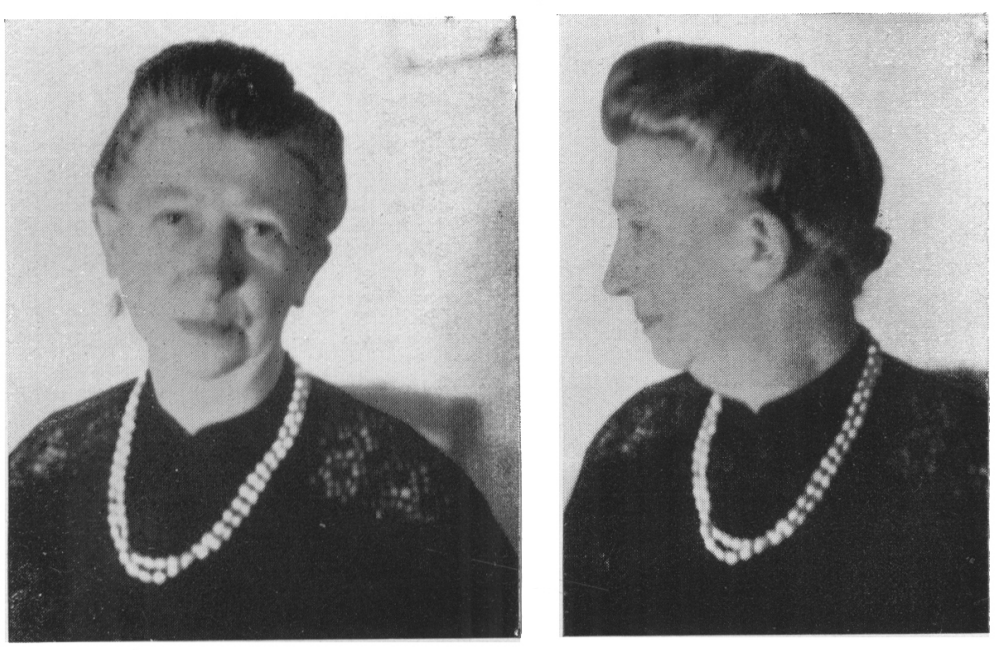

Fig. 3 (II, 5)
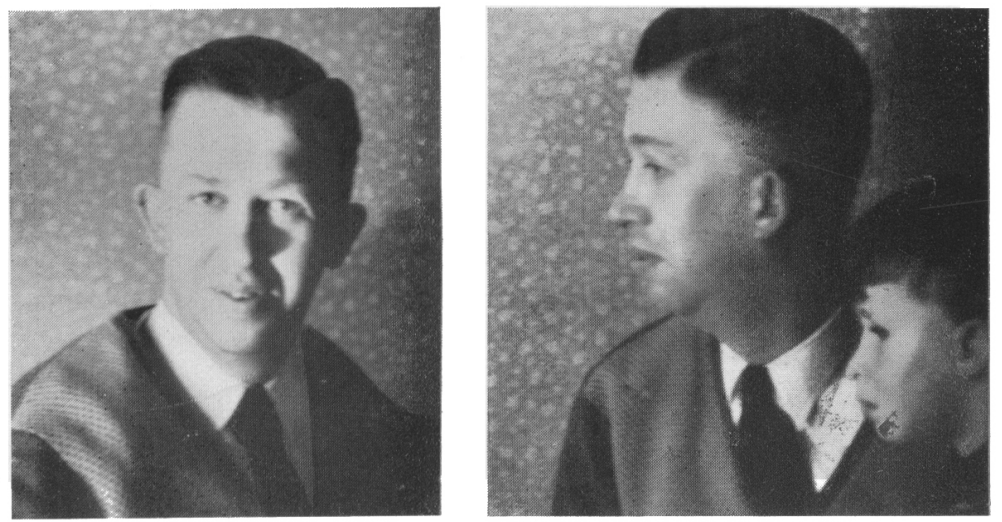

Fig. 4 (III, 2) 
Fig. $5(I I I, 5)$

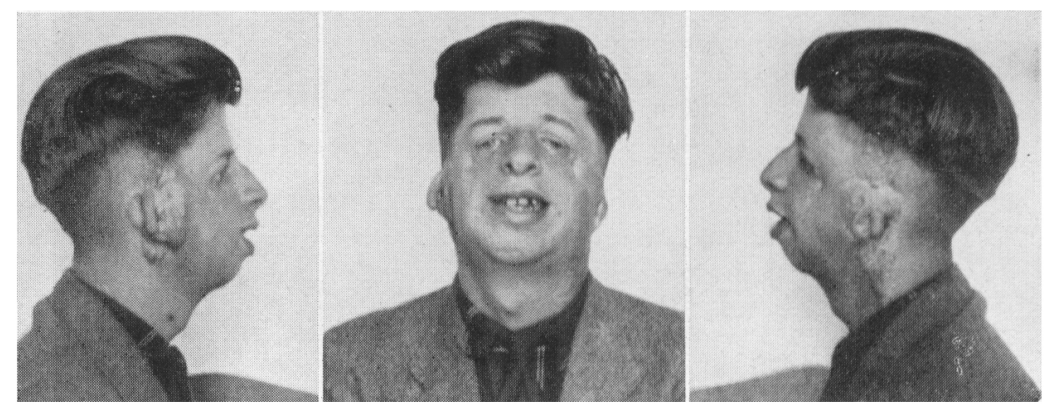

Fig, 6 (III, 5)

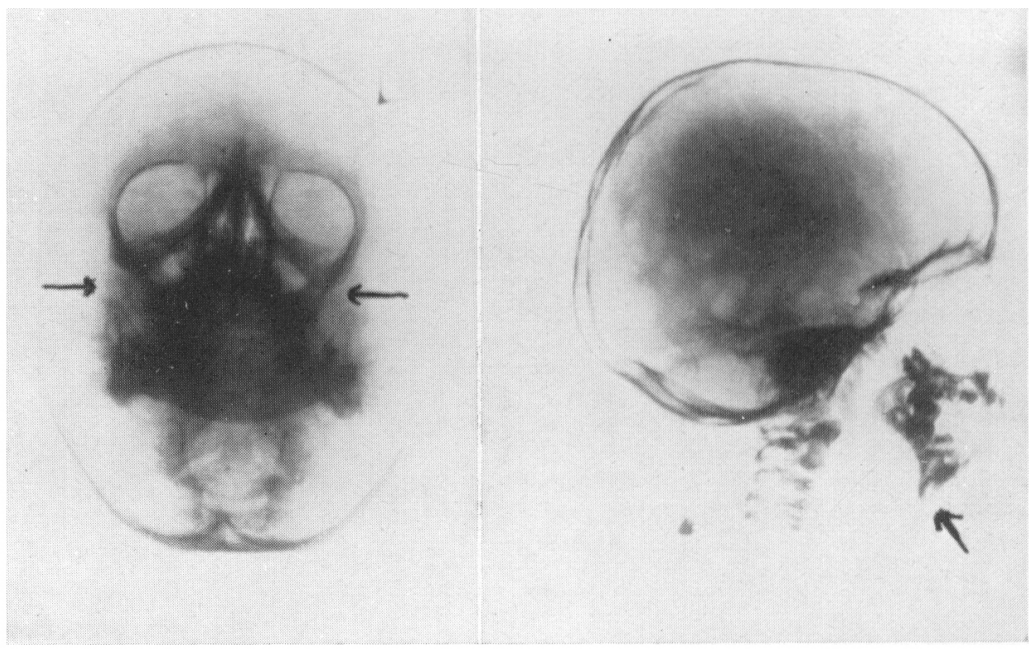

Fig. $7(I V, 2)$
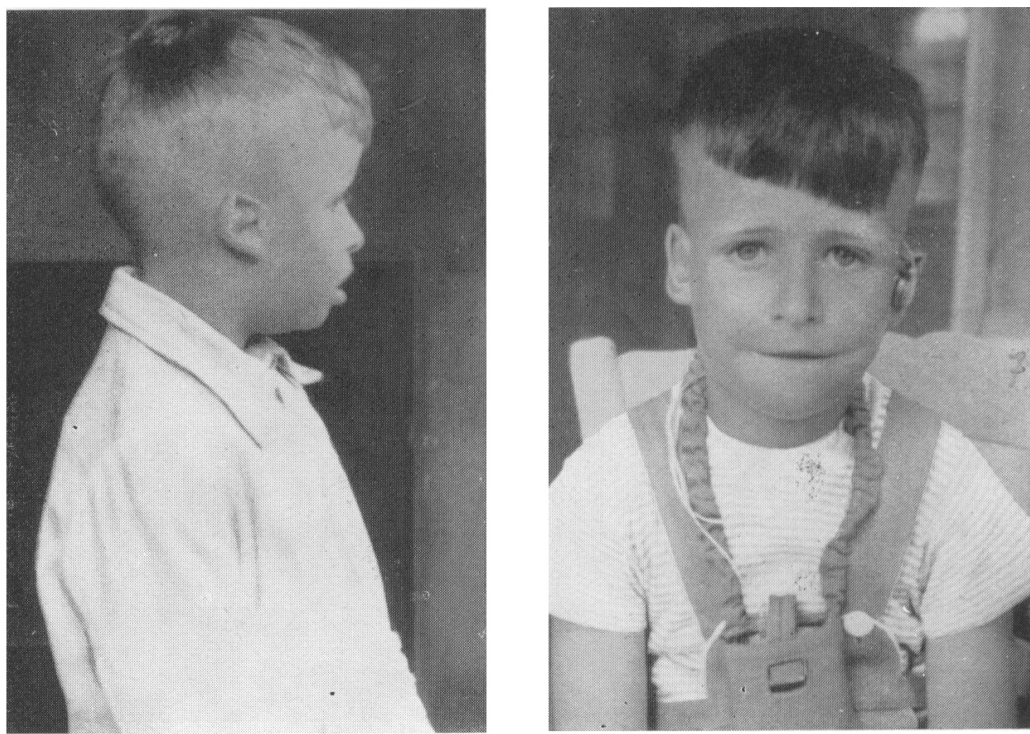
forma! The son of III, 2 shows all the symptoms, the impairment of hearing included, in a severe form, though not in the same degree as his uncle.

Summarizing, we are not qualified to say that there exists in general an obvious change for the worse in the successive generations. This fact is important when we are asked for genetic counseling though we are obliged to tell the affected members of a family that their children may have perhaps $50 \%$ chance to show the syndrome in $a$ more or less severe form. Of course this holds not good for sporadic cases. Mutations may be possible, but this will be most probably an exception.

\section{Summary}

Description of a family five members of which, in four generations show the syndrome mentioned in the title. The mode of inheritance is dominant, with a rather strong penetrance and a great variability in the expressivity. The importance of genetic counseling is stressed.

\section{Literature}

BööK, J. A. and M. Fraccaro (1955): Acta genet., 5, 327.

Debusman (1940): Arch. Kinderheilk., 120, 133.

Franceschetti, A. and D. Klein (I949): Acta ophtalm., 27, Fasc. 2, Separ. pp. 143-224.

Franceschetti, A., D. Klein and J. E. W. Brocher (I959): Schweiz. Med. Wschr., 89, 478.

Freudenberg, E. (195I): Ann. Paed., 1 78, 376.

Hövels, O. (1953): Zschr. Kinderheilk., 73, 532 and 568 .

Leopold, J. H., J. F. Mahoney and M. L. Price (i945): Arch. ophtalm., 34, 2 io.

Nager, F. R. and J. P. de Reijnier (1948): Suppl. 2, Vol. I0, Practica oto-rhino-laryng.

Roussel, F. (1951): Ann. d'oculist., 184, 788.

Schachter, M. (1954): A. Ge. Me. Ge., 3, 236.

Waardenburg, P. and H. Navis (I949): Acta genet. Separ. Vol. I, 2 ig.

Weijers, H. (1956): J. génét. hum., 5, 89.

Zunin, C. (r957): A. Ge. Me. Ge., 7, 483 .

\section{RIASSUNTO}

Descrizione di una famiglia di 4 generazioni in cui cinque membri presentano la sindrome della disostosi mandibolo-facciale. Il modo di trasmissione è dominante con una penetranza piuttosto forte ed una grande variabilità di espressività. Viene sottolineata l'importanza della consulenza genetica.

\section{RÉSUMÉ}

Description d'une famille de quatre générations dans laquelle cinq membres présentent le syndrome de la dysostose mandibulo-faciale. La manière de transmission est dominante avec une pénétrance assez grande et une grande variabilité d'expressivité. L'importance de la consultation eugénique est soulignée.

\section{ZUSAMMENFASSUNG}

Der Verfasser beschreibt eine Familie von vier Generationen in welcher fünf Mitglieder das Syndrom der Dysostosis mandibulo-facialis zeigen. Die Art der Vererbung ist dominant, mit einer ziemlich grossen Penetranz und einer grossen Variabilität der Expressivität. Die Wichtigkeit erbärztlicher Beratung wird hervorgehoben. 